GU J Sci, Part C, 5(4): 145-150 (2017)

Gazi Üniversitesi
Fen Bilimleri Dergisi
PART C: TASARIM VE TEKNOLOJI
dergipark.gov.tr/http-gujsc-gazi-edu-tr

\title{
PDSM Sinyalinin Çoklu Örnekleme Tekniği Kullanılarak Demodülasyonu
}

\author{
Mehmet SÖNMEZ \\ Osmaniye Korkut Ata Üniversitesi, Mühendislik Fakültesi, Elektrik-Elektronik Mühendisliği Bölümü,80010, Merkez/OSMANİYE
}

\begin{abstract}
$\ddot{\mathbf{O} z}$
Makale Bilgisi

Başvuru: $10 / 04 / 2017$

Düzeltme:30/09/2017

Kabul: 30/09/2017

\section{Anahtar Kelimeler}

Kablosuz optik haberleşme sistemleri için modülatör ve demodülatör tasarımı oldukça önemli konulardan birisidir. Yapılan çalışmada VLC (Visible Light Communication: Görünür Işık Haberleşmesi) için kullanılan PDSM (Pulse Dual Slope Modulation: Darbe Çift Eğim Modülasyonu) mimarisi için yeni bir alıcı şeması önerilmiştir. Bu çalışmada çoklu örnekleme tekniği tabanlı demodülatör mimarisi olarak adlandırılan şemanın geleneksel çift örneklemeli demodülatör mimarisine göre daha düşük bit hata oranına $(\mathrm{BHO})$ sahip olduğu görülmüştür. Ancak önerilen demodülatör geleneksel PDSM alıcı yapısına göre daha düşük bit hata oranı performans1 vermektedir Önerilen alıc1 FPGA (Field Programmale Gate Arrays: Alanda Programlanabilir Kapı Dizileri) derleyicisi üzerinde tasarlanmıştır. FPGA derleyicisinin benzetim çıktılarına göre önerilen mimarinin başarılı bir şekilde bilgi bitlerini algıladığı görülmüştür.
\end{abstract}

PDSM,

Demodulator,

$B E R$

\section{Keywords}

\section{PDSM,}

Demodulator, $B E R$

\section{Demodulation of PDSM Signal by Using Multiple Sampling Technique}

\begin{abstract}
The design of modulator and demodulator for wireless optical communication systems is one of the important issues. In this paper, a new receiver scheme is proposed for PDSM (Pulse Dual Slope Modulation) architecture which is used for VLC (Visible Light Communication). It is shown that the scheme that is referred as multiple sampling technique based demodulator architecture in this paper has lower BER (Bit Error Rate) than that of the traditional dual sampling demodulator architecture. However, the proposed demodulator has lower bit error rate performance compared with the traditional PDSM receiver scheme. The proposed receiver is designed on FPGA (Field Programmale Gate Arrays) complier. According to FPGA complier's simulation results, it is shown that the receiver succesfully estimates data bits.
\end{abstract}

\section{GÍRIŞ (INTRODUCTION)}

Görünür 1şık haberleşme sistemleri son zamanlarda kapalı ortam haberleşme sistemleri için birçok araştırmacı tarafindan ilgi duyulan alanlar arasındadır. Görünür 1şık haberleşmesi alıcı tarafta bir fotodedektörün verici tarafta ise bir LED (Light Emitted Diode: Işık Yayan Diyot)'in elektriksel çalışan sistemlere entegre edilmesiyle veri aktarımını sağlayan bir teknolojidir. Bilgi sinyali 1şık enerjisi ile iletiliyorken modülasyon ve demodülasyon süreçleri elektriksel devreler kullanılarak gerçekleştirilmektedir. Günümüz Radyo Frekans (RF) haberleşme sistemleri ile karşılaştırıldığında VLC sistemlerinin en büyük dezavantajı alıcı-verici arasındaki mesafenin daha kısa olmasıdır. Ayrıca alıcı-verici çiftinin birbirini görmesi de tasarlanan haberleşme sisteminin verimliliğini olumlu yönde etkilemektedir. VLC sistemleri için literatürde önerilen modülasyon teknikleri güç tüketimi, titreme, gürültü gibi problemlerin çözümü için kullanılmaktadır. PDSM modülasyon tekniği de titreme problemini çözmek için geliştirilen tekniklerden birisidir [1]. Önerilen yöntem bir sinyalin belirli bir eğim seviyesinde yükselmesini sağlayan modülatör şemasının kullanılmasıyla geliştirilmiştir. Yapılan farklı bir çalışmada, PDSM sinyalinin idle çalışma durumunda sinyalin demodülasyonu için de çift örneklemeli algılayıcı şeması önerilmiştir [2]. LED'in karartma seviyesini ayarlayabilmek için [3]'te yeni bir modülatör şeması önerilmiştir. Önerilen şemada LED'in karartma seviyesi sinyalin genliğinin veya eğiminin değiştirilmesiyle 
sağlanmıştır. Bir kodlama tekniği kullanılarak yeni bir modülatör yapısı önerilen çalışma [4]'te sinyalin demodülasyonu için yeni bir kod çözücü algoritması geliştirilmiştir. Yapılan çalışmada bit sırası ve PDSM sinyalin şekli göz önünde bulundurularak yeni bir kodlanmış sinyal elde edilmiştir. Demodülasyon için alıcı tarafta sinyal kod çözücüden geçirilerek PDSM sinyal elde edilmiştir.

LED parlaklığının değiştirilerek veri bitlerinin PPM (Pulse Position Modulation: Darbe Konum Modülasyonu) tekniği ile iletimi için VPPM (Variable Pulse Position Modulation: Değişken Darbe Konum Modülasyonu) yöntemi geliştirilmiştir [5]. Önerilen yöntem için karartma seviyesi tahmininin alıcı tarafta gerçekleştirilmesine yönelik yapılan çalışmalarda özgün demodülatör tasarımı gerçekleştirmişlerdir. Yapılan bir çalışmada VPPM sinyalinin alıcı tarafta demodülasyonu için erken-geç kapı şeması (early-late gate scheme) geliştirilmiştir [6]. Geliştirilen şemanın dezavantajlarından birisi alıcı tarafta karartma seviyesi bilgisinin olmaması nedeniyle çarpım devresine giren taşıyıcı sinyalin parlaklık oranının doğru ayarlanamamasıdır. Bu eksikliği en düşük seviyeye indirebilmek için yeni bir çalışma alıcı ve verici sistemlerinin birbirine bağımlı bir şekilde çalıştırılmasını içermektedir [7]. Ancak bu çalışmanın dezavantajı ise hedef parlaklık seviyesine ulaşmak için tekrarlayıcı bir yöntem içermesidir.

CMOS (Complementary Metal Oxide Semiconductor: Bütünleyici Metal Oksit Yarı İletken) teknolojisi radyo dalgaları ile yayın yapan birçok alıcı şemasında kullanılmıştır. VLC sistemleri için geliştirilen bir alıc1-verici sisteminde veri iletim oranını artırmak amaciyla CMOS tabanlı alıc1-verici bir sistem tasarlanmıştır. Önerilen yapı MIMO (Multiple Input Multiple Output: Çok Girişli Çok Çıkışlı) sistemi üzerinde uygulanmıştır [8]. Yapılan birçok çalışmada alıcı birim sinyali foto alıcı yerine kamera üzerinden almaktadır $[9,10]$. Kamera kullanılarak tasarlanan alıcıların çoğu paralel veri iletimini artırarak bilgi bitlerinin daha hızlı bir şekilde elde edilmesini amaçlamaktadır.

Yapılan çalışmalar incelendiğinde geleneksel PDSM sinyalin demodülasyonu için literatürde önerilen yöntem çift örneklemeli algılayıcı şemasıdır. Ayrıca geleneksel korelasyon dedektörüne göre çift örneklemeli algılayıcı şeması daha yüksek bit hata oranı vermektedir. Önerdiğimiz mimarinin amacı çift örnek yerine çoklu örnek alan bir alıcı şeması ile bilgi bitlerinin tahmin edilmesidir. Önerilen mimarinin çift örneklemeli algılayıcı şemasına göre daha düşük bit oranına sahip olduğu ancak korelasyon dedektörüne göre daha yüksek bit hata oranı verdiği görülmüştür. Bunun nedeni çift örneklemeli algılayıc1 kaynak [2]'de de görüldüğü gibi sadece iki örneğin genlik değerine göre bilgi bitinin durumuna karar vermektedir. Bu çalışmada önerilen çoklu örneklemeli mimarisi ise bir bit periyodunun yarısı süresince elde edilen iki integral sonucuna göre karar vermektedir. Karmaşıklık açısından karşılaştırıldığında önerilen yöntem korelasyon dedektörüne göre daha düşük kompleks yapıda olmasına rağmen çift örneklemeli yapıya göre daha yüksek karmaşıklığa sahiptir. Çünkü korelasyon dedektöründe gelen sinyal ile taşıııı sinyallerin çarpılması için yeniden taşıyıcı sinyal üretimi gerekmektedir. Ancak bu çalışmada önerilen yöntemde taşıyıcı sinyaller yeniden üretilmeden doğrudan gelen modülasyonlu PDSM sinyalinden örneklerin alınmasıyla bilgi bitleri algılanmaktadır. Önerilen PDSM demodülatörü FPGA derleyicisi üzerinde tasarlanmış olup, önerilen yöntemin donanımsal uygulanması için yeni bir mantıksal devre tasarımı gerçekleştirilmiştir. Benzetim çıktılarından önerilen yöntemin başarılı bir şekilde çalıştığı izlenmiştir.

\section{PDSM ŞEMASI (PDSM SCHEME)}

PDSM tekniği LED'in titreşimini engellemek için önerilmiştir. Titreşimi engelleyebilmek için PDSM mimarisi hem '1' bilgi sinyali, hem '0' bilgi sinyali, hem de boş (idle) durumu için bir periyotluk sürede eşit ortalama değere sahip sinyaller üretmektedir. Bu nedenle LED parlaklığg değişmemektedir. Şekil 1'de PDSM tekniği için kullanılan sinyallerin durumu verilmektedir.

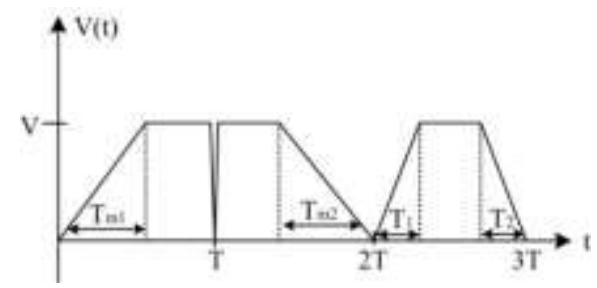

Şekil 1. PDSM dalga şekli 
Şekil 2'de '1', '0' bilgi sinyalleri ve idle durumu için üç farklı sinyal şekli verilmektedir. Şekilde verilen eğimlerin birbiriyle ilişkisi denklem (1)'de verildiği gibidir.

$m=\frac{V}{T_{m 1}}=\frac{V}{T_{m 2}}=\frac{V}{2 T_{1}}=\frac{V}{2 T_{2}}$

Denklem (1)' de $m$, PDSM sinyalinin eğimini göstermektedir. $T_{m 1}$ ve $T_{m 2}$ ise sirasılyla '1' ve '0' bilgi sinyallerinin iletimi için kullanılan taşıyıcı sinyallerin yükselme süresini ve $T_{1}$ ile $T_{2}$ ise idle sinyalinin yükselme ve düşme sürelerini göstermektedir. Şekilden görüldüğ̈̈ gibi idle sinyal ile bilgi bitlerinin iletimi için geçen süreler birbirlerine eşittir. Ancak idle sinyalinin yükselmesi ve düşmesi için gerekli süre, bilgi bitlerinin iletiminde kullanılan taşıyıcı sinyallerin yükselme veya düşme sürelerinin iki katı kadardır. Bunun nedeni titreme etkisini düşürmek için önerilen PDSM modülasyon tekniğinde idle sinyal ile bilgi biti iletimini sağlayan sinyallerin bir bitlik periyot süresince integral sonuçlarının eşit olmasını sağlamak için gerçekleştirilmiştir.

\section{3. ÖNERILEN PDSM DEMODÜLATÖR MIMARİSI (PROPOSED PDSM DEMODULATOR ARCHITECTURE)}

PDSM sinyalinin demodülasyonu için korelatör tabanlı mimari ve çift örneklemeli algılama tekniği kullanılmaktadır. Çift örneklemeli algılama (DSD: Dual Sampling Detection) tekniği ilk kez [2] çalışmasında önerilmiştir. Önerilen teknik, sembol süresince son örnekten bir önceki örnek ile ilk örnekten bir sonraki örneğin arasındaki fark değeri incelenerek çalışmaktadır. Bu çalışmada önerilen mimaride ise iki örnek yerine bütün örnek değerleri alınarak bilgi sinyalinin demodülasyonu sağlanmaktadır. Belirli bir süreden önce alınan örnek değerlerinin toplam değeri, belirlenmiş süreden sonra gelen örnek değerlerinin toplam değerinden çıkarılır. Bu sayede simetrik bir şekilde örneklerin farkları alınarak, elde edilen değerlerin toplamları üzerinden bilgi bitleri tahmin edilebilmektedir. Geleneksel çift örneklemeli modülasyon tekniğine göre daha iyi bir sonuç vermesinin nedeni iki örnekten fazla örneğin karşılaştırılmasıdır. Bu nedenle kanal veya foto alıcı kaynaklı ani gürültülerin örneğin değerini değiştirmesi pek fazla önem arz etmeyecektir. Önerilen mimarinin blok şeması Şekil 2'de verildiği gibidir.

Şekil 2'de verilen mimaride sinyal iki farklı integratör girişine uygulanmıştır. Şekilden de görüldügü gibi en (yetkilendirme) sinyali sayesinde integral alıcılardan birisi çalışırken diğeri sabit bir çıkış vermektedir. Bunun nedeni önerilen mimarinin sembol periyodunun belirli bir süresinde gelen sinyalin toplam değeri ile farklı bir süre boyunca gelen sinyalin toplam değerlerinin karşılaştırılmasıdır. Gelen sinyallerin integral değerleri alındıktan sonra bir $K$ karşılaştırıcı devresi yardımıyla demodülasyonlu bitler elde edilmektedir. Birinci zaman süresinde Integral-2 bloğu aktif durumdadır. Bu durumda integral değerinin maksimum olması pozitif eğime sahip bir sinyalin olduğunu göstermektedir. Dolayısıly iletilen bilgi biti '1' olmaktadır. Diğer durumda Integral-I bloğu iletimde olup sinyalin eğiminin pozitif olduğu durum

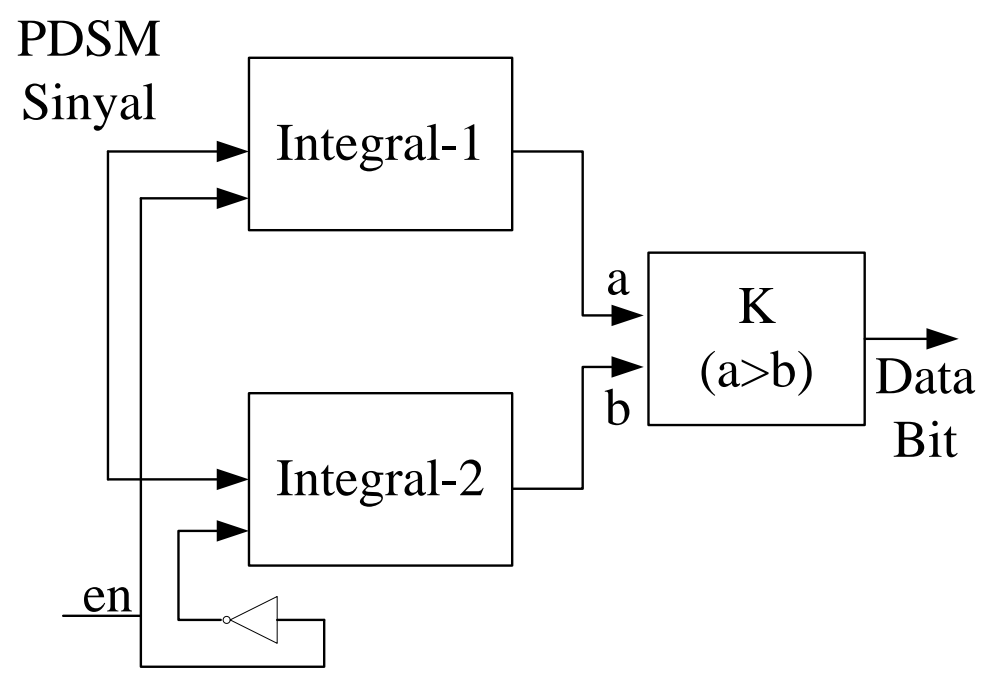

Şekil 2. Önerilen PDSM demodülatör mimarisi 
integratörünün çıkışının maksimum olduğu durumdur. Veri bitinin '0' olması negatif eğime sahip bir sinyalin iletildiğini göstermektedir. Önerilen mimari için matematiksel ifade denklem (2), (3) ve (4)'te verildiği gibidir.

$$
\begin{aligned}
& I_{1}=\sum_{k=i+1}^{z} s[k] \\
& I_{2}=\sum_{k=1}^{i} s[k] \\
& d(t)= \begin{cases}\prime & \text { if } I_{1}>I_{2} \\
{ }^{\prime} & \text { else }\end{cases}
\end{aligned}
$$

Denklem (2) ve (3)'te $\mathrm{I}_{1}$ ve $\mathrm{I}_{2}$ sırasıyla Integral-1 ve Integral-2 bloklarının işlevlerini yerine getirmektedir. Şekilde $i$ değeri sembol periyodunun yarısı süresince alınan örnek sayısını, $z$ değeri de bütün sembol periyodu süresince alınan örnek sayısını ifade etmektedir. Denklemlerde $k$ değeri ise o andaki örneğin sırasını göstermektedir. Şekil (4)'te ise bir karşılaştırma verilmiş olup integral alıcı çıkışlarının alacağı değere göre karar devresinin bilgi bitini tahmini açıklanmıştır. Denklem 4'ten de görüldüğü gibi $I_{1}$ integral çıkışının $I_{2}$ integral çıkışından büyük olması halinde bilgi sinyali ' 1 ' olup diğer durumda ' 0 ' dır.

\section{PDSM DEMODÜLATÖR MIMARİSI IÇİN BENZETIM SONUÇLARI (SIMULATION RESULTS OF PDSM DEMODULATOR ARCHITECTURE)}

Yapılan çalışmada önerilen mimarinin tasarımı Quartus programı yardımıyla gerçekleştirilmiş olup, AlteraModelsim benzetim programında da sonuçlar analiz edilmiştir. Şekil 3’te, önerilen PDSM demodülatörü için elde edilmiş benzetim sonuçları görülmektedir.

Şekil 3'te $s \_s$ sinyali saat sinyalini göstermektedir. Ayrıca gönderilecek bit grubunun (giris_b), alıcı tarafta demodüle edilmiş bit grubu (demod_bit) ile aynı olması başarılı bir şekilde demodülasyonun gerçeklendiğini göstermektedir. Şekilde $d \_$out sinyali bit grubu giris_b sinyalinin zamanda ayıklaştırılmış şeklini vermektedir. Şekilden görüldüğg̈ gibi $d \_o u t$ sinyali '1' olduğunda iletilecek olan $p d s m$ sinyali pozitif eğime sahip bir sinyalden oluşuyorken, diğer durumda $p d s m$ sinyalinin eğimi negatif yöndedir. $I_{1}$ ve $I_{2}$ sinyalleri ise birinci ve ikinci integral alıcı çıkışlarını vermektedir. Şekilden görüldüğü gibi birinci yarım sembol süresince $I-2$ integral alıcısı aktif durumdayken, diğer yarım bit periyotluk süreçte $I$ - $I$ integral alıcısı aktif durumdadir.

Önerilen demodülatör mimarisi ile geleneksel demodülatör mimarisinin bit hata oranı performansları karşılaş̧ırılmıştır. Karşılaştırma sonucuna göre önerilen tasarım geleneksel çift örneklemeli demodülatör mimarisinden daha iyi bir BHO performansına sahiptir. Bunun nedeni bir
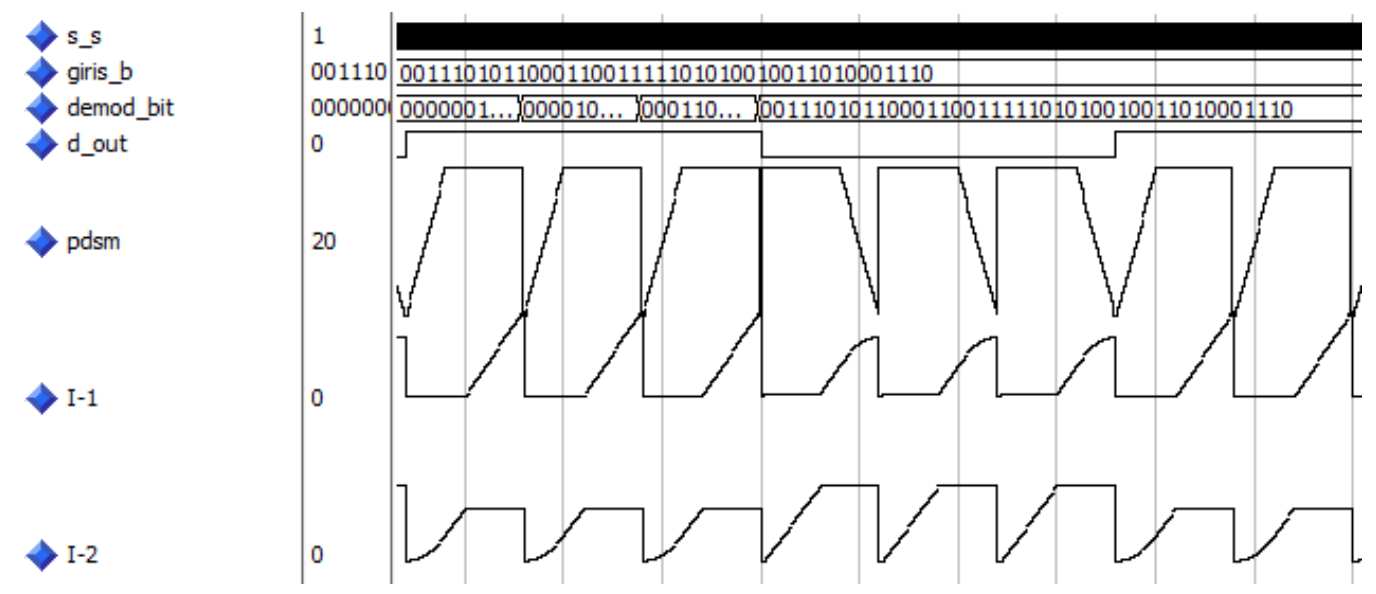

Şekil 3. Önerilen PDSM demodülatörü için benzetim sonuçları 


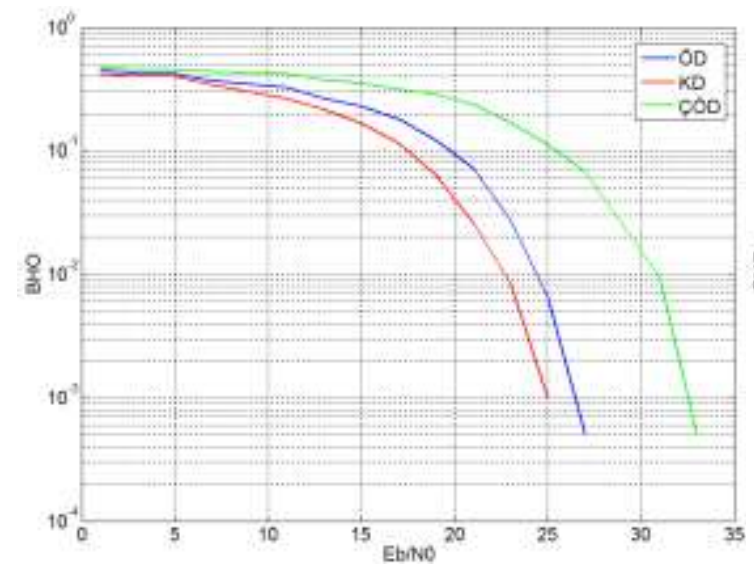

(a)

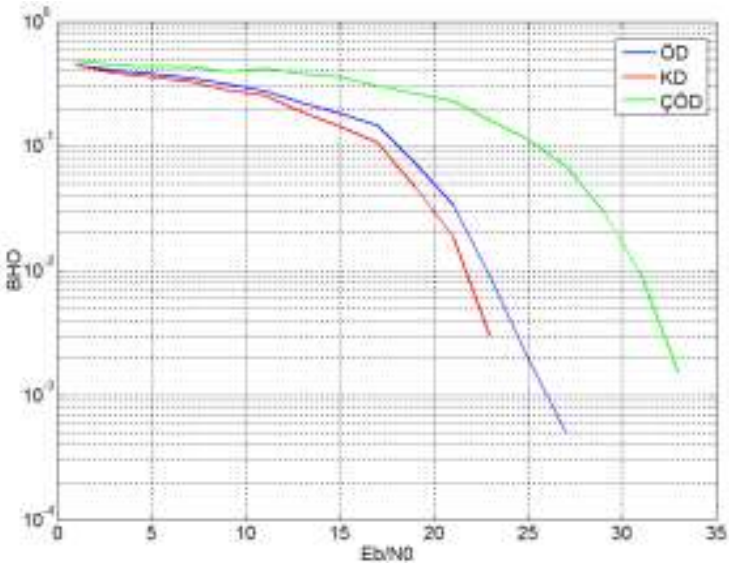

(b)

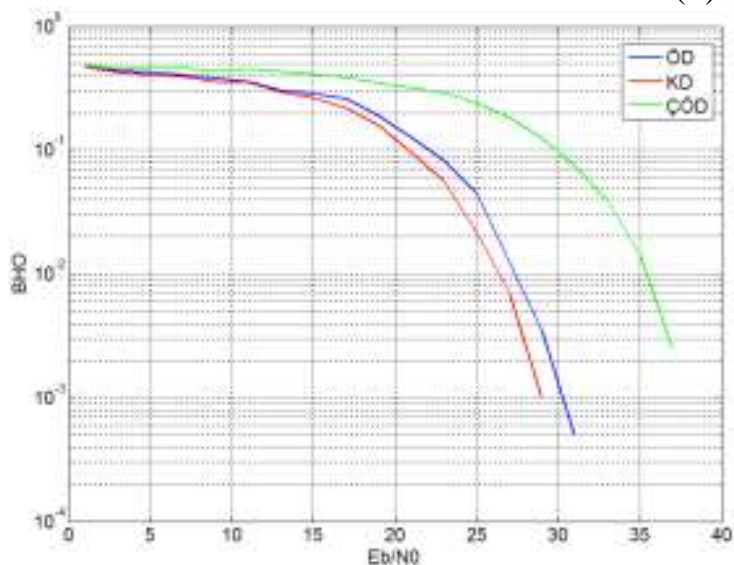

(c)

Şekil 4. BHO benzetim sonuçları. (a) \%70 parlaklık seviyesi. (b) \%50 parlaklık seviyesi (c) \%30 parlaklık seviyesi

önceki bölümde açıklandığı gibi iki örneğin karşılaştırılması yerine bütün örneklerin işleme alınmasıdır. $\mathrm{Bu}$ nedenle ancak en iyi sonucu korelatör tabanlı demodülatör mimarisinin verdiği görülmüştür. Gerçeklenen çalışmada parlaklık oran değeri $0.3,0.5$ ve 0.7 değerlerine göre $\mathrm{BHO}$ performans sonuçları verilmiştir.

Şekil 4’te görülen sonuçlardan önerilen yöntemin (Ö.D), çift örneklemeli algılayıcıya (ÇÖD) göre daha iyi bir BHO performansı verdiği görülmektedir. Ancak korelatör tabanlı algılayıcıya (KD) göre daha düşük başarımlı bir BHO performansına sahip olduğu görülmüştür.

\section{SONUÇ (CONCLUSION)}

Yapılan çalışmada VLC sistemlerinde kullanmak için yeni bir PDSM alıcı şeması önerilmiştir. Bu çalışmada önerilen şemanın geleneksel çift örneklemeli demodülatör mimarisine göre daha düşük bit hata oranına sahip olduğu görülmüştür. Ancak önerilen yöntem çift örneklemeli demodülatör mimarisine göre daha karmaşık bir yapıda olup, geleneksel mimariye göre daha sade bir şemadır. Geleneksel PDSM alıcı mimarisinin taşıyıcı sinyalleri yeniden üretmesi, modülasyonlu sinyal ile ürettiği taşıyıcı sinyalleri çarpım ve integral alıcı devrelerinden geçirmesi karmaşıklığını artırmaktadır. Bu çalışmada önerilen çoklu örnekleme tekniğinin karmaşıklığını ise integratör blokları artırmaktadır. Çift örneklemeli demodülatör mimarisinde iki integratör yerine örnekle ve tut devresi kullanılmıştır [2]. Ayrıca yapılan çalışmada, önerilen alıcının FPGA donanımı üzerinde uygulanabilmesi için yeni bir mantıksal devre tabanlı tasarım önerilmiştir.

\section{KAYNAKLAR (REFERENCES)}

1. M A. ve Mishra P., A Novel Modulation Scheme for Visible LightCommunication", 2010 Annual IEEE India Conference (INDICON), Kolkata, India, 1-3, 17-19 Aralık 2010. 
2. Oh M., "Pulse Dual Slope Modulation for VLC. KSII Tran. Internet and Information Systems, 8: 4 (2014), 1276-1291.

3. M A. ve N. Kumar, "New, Effective and Efficient Dimming and Modulation Technique for Visible Light Communication", IEEE 79th Vehicular Technology Conference (VTC Spring), Seoul, Korea, 1-4, 18-21 May1s 2014.

4. Park K.H., Li C., Alouini M.S., "Performance comparison of binary modulation schemes for visible light communication" IEEE International Conf. on Commun. (ICC15), London, England, 5036-5041, 8-12 Haziran 2015.

5. IEEE Standard 802.15.7-2011, pp. 1-309, Jun. 2011.

6. Noh, J., Lee, S., Kim, J. Ju, M., Park, Y., A dimming controllable VPPM-based VLC system and its implementation. Optics Commun., 343 (2015), 34-37.

7. Lee, S., Ahn, B.G., Ju, M.C., Park, Y., A modified VPPM algorithm of VLC systems suitable for fast dimming environment. Optics Commun., 365 (2016), 43-48.

8. Sujan R., Hyunchae C., Grahame F., Katherine C., Aravind V. N. J., Robert H., Dobroslav T., Muhammad I., Zhe C., Harald H., Enyuan X., Jonathan J. D. M., Johannes H., Erdan G., Martin D. D., Dominic O. B., High-Speed Integrated Visible Light Communication System: Device Constraints and Design Considerations. IEEE J. on Selected Areas in Communications, 33: 9 (2015), 1750-1757.

9. Shivani T., Willy A. C., Yeon H. C., Optical Camera Communication: Motion over Camera. IEEE Communications Magazine, 55: 8 (2017), 156-162.

10. Yanbing Y., Jie H., Jun L., CeilingTalk: Lightweight Indoor Broadcast through LED-Camera Communication. IEEE Tran. on Mobile Computing, PP: 99 (2017), 1-12. 